UDC 343

LBC 67.408

\title{
AGGRAVATING CIRCUMSTANCES AS A MEANS OF DIFFERENTIATING CRIMINAL RESPONSIBILITY
}

\author{
Kirill A. Dolgopolov \\ Nevinnomyssk State Humanities and Technical Institute, Nevinnomyssk, Russian Federation
}

Introduction: it is difficult to overestimate the importance for the criminal case of materials received by operational units at the stage of preliminary verification of information, in connection with which the author has to consider the influence of aggravating circumstances on the appointment of criminal punishment, and also consider aggravating circumstances as a means of differentiating criminal responsibility.

Methods: the methodological basis of this study is a set of methods of scientific knowledge, among which the main place is occupied by methods of system, analysis and comparative-legal.

Results: the analysis of the institution of aggravating circumstances carried out by the authors made it possible to conclude that any aggravating circumstance should be taken into account by the court when choosing a measure of criminally-legal effect.

Conclusions: according to the results of the work, it is shown that aggravating circumstances are an independent criminal responsibility differentiated by the institution, which is most fully used inthe individualization of responsibility and promotes the implementation of the principles of justice and humanism. In accordance with the principles of criminal law, the list of aggravating circumstances is considered exhaustive, and any circumstance indicating an increase in the public danger of the offense and the person of the perpetrator, to be taken into account by the court when choosing a measure of criminal law influence, must necessarily be named therein.

Key words: punishment, punishment, aggravating circumstances.

УДК 343

ББК 67.408

\section{ОТЯГЧАЮЩИЕ ОБСТОЯТЕЛЬСТВА КАК СРЕДСТВО ДИФФЕРЕНЦИАЦИИ УГОЛОВНОЙ ОТВЕТСТВЕННОСТИ}

\author{
Кирилл Андреевич Долгополов \\ Невинномысский государственный гуманитарно-технический институт, \\ г. Невинномысск, Российская Федерация
}

\begin{abstract}
Введение: трудно переоценить значение для уголовного дела материалов, полученных оперативными подразделениями на этапе предварительной проверки информации, в связи с чем автором в работе поставлена цель рассмотреть влияние отягчающих обстоятельств на назначение уголовного наказания, а также рассмотреть отягчающие обстоятельства как средство дифференциации уголовной ответственности.

Методы: методологическую основу данного исследования составляет совокупность методов научного познания, среди которых основное место занимают методы системности, анализа и сравнительно-правовой.

Результаты: проведенный авторами анализ института отягчающих обстоятельств позволил сделать вывод о том, что любое отягчающее обстоятельство должно учитываться судом при избрании меры уголовно-правового воздействия.

Выводы: по итогам работы показано, что отягчающие обстоятельства являются самостоятельным дифференцирующим уголовную ответственность институтом, который наиболее полно применяется при индивидуализации ответственности и способствует реализации принципов справедливости и гуманизма. В соответствии с принципами уголовного права перечень отягчающих наказание обстоятельств признается исчерпывающим, и любое обстоятельство, свидетельствующее о повышении общественной опасности преступления и личности виновного, чтобы учитываться судом при избрании меры уголовно-правового воздействия, должно быть обязательно названо в нем.

Ключевые слова: наказание, назначение наказания, отягчающие обстоятельства.
\end{abstract}




\section{Введение}

При рассмотрении вопросов дифференциации уголовной ответственности в юридической литературе наряду с аспектами ее индивидуализации, пределов и т. д. рассматриваются средства дифференциации, но практически не уделяется внимание изучению дифференцирующих ответственность обстоятельств как комплекса условий реализации дифференцирующих норм. Если средства касаются воздействия на санкцию, например, путем кратного изменения ее границы, обстоятельства содержатся в диспозиции и являются условием применения дифференцирующей нормы.

Дифференцируют уголовную ответственность и наказание своими средствами многие институты как Общей, так и Особенной частей Уголовного кодекса РФ (УК РФ). Они определяют ответственность за основной состав преступления и ее изменение при наличии определенных обстоятельств [3].

\section{Основное содержание}

В Общей части к таким институтам можно отнести: множественность преступлений; неоконченную преступную деятельность; соучастие; обстоятельства, смягчающие наказание; обстоятельства, отягчающие наказание; условное осуждение и условно-досрочное освобождение от отбывания наказания; освобождение от уголовной ответственности по нереабилитирующим основаниям; освобождение от наказания; замену наказания более мягким; отсрочку отбывания наказания; давность обвинительного приговора; амнистию; несовершеннолетие; судимость и др.

В Особенной части к средствам дифференциации можно отнести выделение квалифицированных и привилегированных составов, а также специальные виды освобождения от ответственности.

Мы не склонны относить к дифференциации те случаи, когда предусматривается различная ответственность, но не дифференцируется (форма вины), когда институт влияет на дифференциацию или используется в этих целях опосредованно через другие институты (категоризация преступлений), когда об- стоятельства являются необходимым условием ответственности (вменяемость), когда классифицируются наказания по видам или классифицируются, распределяются преступления по видам [2].

Дифференцирующие обстоятельства служат условием применения перечисленных дифференцирующих норм, то есть при наличии таких обстоятельств они должны или могут, в зависимости от степени императивности нормы, применяться правоприменителем в определенном направлении. При этом одни и те же обстоятельства иногда содержатся в различных дифференцирующих институтах и могут применяться совокупно или альтернативно. Так, несовершеннолетний возраст предусматривает одновременное использование множества дифференцирующих институтов (как смягчающее обстоятельство и как основание для применения положений гл. 14 УК РФ), хотя, по общему правилу, обстоятельства, которые могут выступать как квалифицирующие их как отягчающие или как смягчающие и привелигирующие, не могут учитываться дважды.

Некоторые дифференцирующие нормы не содержат дифференцирующих обстоятельств. Так, вердикт присяжных о снисхождении или особом снисхождении, амнистия и помилование дифференцируют ответственность, предусматривают ее изменение в определенном направлении, но в законе не сказано, по каким основаниям это делается, тоесть дифференцирующих обстоятельств в них не содержится. Представляется нецелесообразной дифференциация уголовной ответственности без четко сформулированных дифференцирующих обстоятельств непосредственно в законе.

В то же время некоторые дифференцирующие обстоятельства принадлежат к институтам, которые сами по себе уголовную ответственность не дифференцируют, но эти обстоятельства применяются в качестве дифференцирующих в других институтах как универсальное обстоятельство. Так, категоризация преступлений классифицирует все преступления на виды в зависимости от максимума санкции. Такую классификацию нельзя назвать саму по себе дифференциацией уголовной ответственности. Однако это одно из 


\section{ПРОТИВОДЕЙСТВИЕ ПРЕСТУПНОСТИ}

дифференцирующих обстоятельств, и многие дифференцирующие нормы содержат в качестве условия дифференциации конкретные категории преступлений (например, в разделе 4 УК РФ).

Содержащиеся в уголовном законе дифференцирующие обстоятельства можно классифицировать по разным основаниям. Так, по направлению влияния на изменение объема ответственности мыслимо выделение снижающих и повышающих ответственность обстоятельств. По содержательному моменту дифференцируемой ответственности нужно различать обстоятельства, относящиеся к субъективной и объективной сфере. Различна частота употребления в законе тех или иных обстоятельств [1].

Наиболее информативна классификация данных обстоятельств по сущностным характеристикам, которые отражают и их криминологическую обоснованность. По данному основанию можно выделить следующие виды дифференцирующих обстоятельств: 1) отражающие изменение степени и характера общественной опасности совершенного деяния; 2) изменяющие степень общественной опасности лица, совершившего преступление; 3) влияющие на ответственность в силу принципа гуманизма.

В соответствии с задачами уголовного законодательства и целями наказания и уголовной ответственности, можно предложить более дробную классификацию дифференцирующих уголовную ответственность обстоятельств в уголовном законе:

I. Обстоятельства, отражающие устойчивые характеристики (статус) личности виновного:

1) возраст (несовершеннолетний, престарелый и др.);

2) пол;

3) должностное положение и другие виды специальных субъектов;

4) беременность или наличие малолетних детей у женщины;

5) условия жизни семьи.

II. Индивидуальные, характеризующие личность данные, которые проявились при совершении преступления:

1) мотив совершения преступления (сострадание, национальная, расовая или религи- озная вражда и ненависть, с целью скрыть или облегчить совершение другого преступления, месть за правомерное или связанное со служебной деятельностью поведение);

2) роль при совершении преступления в соучастии;

3) привлечение к совершению преступления лиц, не являющихся субъектами (п. «Д» ч. 1 ст. 63 УК РФ);

4) жестокость, садизм, причинение мучений;

5) использование беспомощного состояния потерпевшего или осознание особо охраняемого статуса потерпевшего;

6) использование оружия и других средств;

7) использование принуждения, доверия;

8 ) использование форменной одежды, документов представителя власти.

III. Обстоятельства, влияющие на степень и характер общественной опасности преступного деяния:

1) неоконченная преступная деятельность;

2) соучастие;

3) извинительные условия (превышение пределов необходимой обороны, превышение мер, необходимых для задержания преступника, превышение пределов крайней необходимости, причинение вреда под принуждением при возможности руководить своими действиями или в силу зависимости, нарушение условий правомерности обоснованного риска и исполнения приказа или распоряжения);

4) противоправность или аморальность поведения потерпевшего;

5) тяжкие последствия совершенного преступления.

IV. Постпреступное поведение виновного:

1) явка с повинной, деятельное раскаяние, способствование раскрытию преступления, оказание медицинской помощи потерпевшему, возмещение ущерба и вреда, примирение с потерпевшим;

2) добровольный отказ организатора или подстрекателя, если не удалось предотвратить преступление;

3) неисполнение возложенных судом обязанностей или принудительных мер воспитательного воздействия, уклонение от исполнения наказания, поведение при отбывании наказания. 
V. Объективные условия (обстановка), влияющие на ответственность:

1) случайное стечение обстоятельств или стечение тяжелых жизненных обстоятельств;

2) условия чрезвычайного положения, стихийного или иного общественного бедствия, массовых беспорядков;

3) объективное изменение обстановки;

4) истечение срока давности;

5) тяжелая болезнь;

6) амнистия.

Данную классификацию нужно признать примерной, так как многие обстоятельства одновременно характеризуют личность и влияют на степень общественной опасности преступления. Поэтому отнесение подобных обстоятельств к той или иной категории условно, но оно отражает основные сущностные моменты дифференцирующих обстоятельств, используемых для достижения целей уголовной ответственности и наказания.

Обобщенно все перечисленные основания изменения ответственности можно разделить на две категории.

Во-первых, это те обстоятельства, которые объективны по отношению к виновному, так как не зависят от него и влияют на ответственность, исходя из установленных презумпций, принципа гуманизма или особой охраны законом объектов и субъектов. К таковым можно отнести: пол, возраст, тяжелые жизненные обстоятельства, чрезвычайные условия, изменение обстановки, статус и т. д.

Во-вторых, это такие обстоятельства, которые предполагают возможность выбора поведения, и при их наличии позволяют субъекту получить освобождение от ответственности или смягчить ее на любой стадии с момента подготовки преступления и до погашения судимости за него.

Таким образом, вторая категория дифференцирующих обстоятельств обусловлена, в основном, целями уголовной ответственности и наказания, то есть превенцией, достижением социальной справедливости и исправлением виновного. При этом поведение субъекта с момента приготовления к преступлению и до момента появления в распоряжении следствия или дознания достаточных данных, позволяющих предъявить ему обвинение, определяет (наряду с ква- лификацией деяния) то, какие необходимы первоначальные меры ответственности к данному субъекту. В дальнейшем поведение субъекта позволяет корректировать и даже исключать такие меры, если цели уголовной ответственности и наказания достигнуты. Данная категория дифференцирующих обстоятельств должна быть приоритетной, так как эти обстоятельства способствуют общей и частной превенции, ориентируют лицо на правопослушное поведение на любой стадии постпреступного поведения и реализации уголовной ответственности.

\section{Выводы}

Проведенное исследование позволяет сделать вывод о том, что отягчающие обстоятельства являются самостоятельным дифференцирующим уголовную ответственность институтом, который наиболее полно применяется при индивидуализации ответственности и способствует реализации принципов справедливости и гуманизма. В соответствии с принципами уголовного права, перечень отягчающих наказание обстоятельств признается исчерпывающим, и любое обстоятельство, свидетельствующее о повышении общественной опасности преступления и личности виновного, чтобы учитываться судом при избрании меры уголовно-правового воздействия, должно быть обязательно названо в нем.

\section{СПИСОК ЛИТЕРАТУРЫ}

1. Васильевский, А. В. Дифференциация уголовной ответственности и наказания в Общей части уголовного права : дис. ... канд. юрид. наук / Васильевский Александр Валентинович. - Ярославль, 2000. -219 c.

2. Кругликов, Л. Л. О средствах дифференциации ответственности в Общей части Уголовного кодекса РФ / Л. Л. Кругликов. - М., 1999. - 55 с.

3. Лесниевски-Костарева, Т. А. Дифференциации уголовной ответственности / Т. А. Лесниевски-Костарева. - М. : НОРМА, 2000. - 400 с.

\section{REFERENCES}

1. VasilievskiyA.V. Differentsiatsiya ugolovnoy otvetstvennosti i nakazaniya $v$ Obshchey chasti ugolovnogo prava: diss. ... kand. yurid. nauk 


\section{ПРОТИВОДЕЙСТВИЕ ПРЕСТУПНОСТИ}

[Differentiation of Criminal Responsibility and Punishmentin in the General Part of Criminal Law. Cand. jurid. sci. diss.]. Yaroslavl, 2000. 219 p.

2. Kruglikov L.L. O sredstvakh differentsiatsii otvetstvennosti $v$ Obshey chasti Ugolovnogo kodeksa RF [On the Means of Differentiating
Responsibility in the General Part of the Criminal Code of the Russian Federation]. Moscow, 1999. $55 \mathrm{p}$.

3. Lesnievski-Kostareva T.A. Differentsiatsiya ugolovnoy otvetstvennosti [Differentiation of Criminal Responsibility]. Moscow, Norma Publ., 2000. 400 p.

\section{Information about the Author}

Kirill A. Dolgopolov, Candidate of Sciences (Jurisprudence), Associate Professor, Head of Department of Criminal Procedure and Criminalistics, Nevinnomyssk State Humanities and Technical Institute, Mira Blvd., 17, 357108 Nevinnomyssk, Russian Federation, nada106@mail.ru.

\section{Информация об авторе}

Кирилл Андреевич Долгополов, кандидат юридических наук, доцент, заведующий кафедрой уголовного процесса и криминалистики, Невинномысский государственный гуманитарно-технический институт, Бульвар Мира, 17, 357108 г. Невинномысск, Российская Федерация, nada106@mail.ru. 